\title{
Treatment of prehypertension: lifestyle and/or medication
}

This article was published in the following Dove Press journal:

Vascular Health and Risk Management

14 November 2012

Number of times this article has been viewed

\author{
Scott R Collier' \\ Michael J Landram² \\ 'Vascular Biology and Autonomic \\ Studies Laboratory, Appalachian \\ State University, Boone, NC, USA; \\ 2Università degli Studi di Roma "Foro \\ Italico", Rome, Italy
}

\begin{abstract}
Prehypertension is a warning to individuals with resting blood pressures between $120 / 80 \mathrm{mmHg}$ and $139 / 89 \mathrm{mmHg}$ of an insidious progression of blood pressure towards hypertensive levels ( $\geq 140 / 90 \mathrm{mmHg}$ ). Prehypertension is associated with increased cardiovascular risk and end organ damage compared with individuals who are normotensive. This review primarily focuses on internal and external factors associated with the prevalence of prehypertension. Elucidating all of the factors associated with a rise in resting blood pressure and comparing the effects of medication versus lifestyle changes may aid the clinician in developing a preventive and/or treatment strategy for each individual.
\end{abstract}

Keywords: sex differences, blood pressure, lifestyle changes

\section{Introduction}

The Seventh Report of the Joint National Committee on Prevention, Detection, Evaluation, and treatment of High Blood Pressure (JNC-7) has revised its classifications of high blood pressure (BP) to include "prehypertension" as a category that was formerly covered by both the "normal" and "borderline" groups. ${ }^{1}$ It is well known that if prehypertension remains undetected, chronically elevated BP levels can increase the risk of developing cardiovascular disease. Longitudinal data from the Framingham Heart Study have indicated that BP values of 130-139/85-89 mmHg (now considered "prehypertensive" according to the new JNC-7 guidelines) are associated with a more than two-fold increase in relative risk of cardiovascular disease as compared with those with BP levels below 120/80 mmHg. ${ }^{1}$ Even considering the potential increase in risk factors for cardiovascular disease, prehypertension is not a disease category. JNC-7 states that it is a designation chosen to identify individuals at high risk of developing hypertension, so that both the patient and clinician are alerted to this risk and can work to intervene and prevent or delay development of the disease. However, it is asserted that lifestyle modification should be pursued over pharmacological intervention unless a secondary disease is present (eg, type 2 diabetes mellitus or kidney disease). Additional changes that result in increased BP stem from pathological arteriolar hypertrophy. ${ }^{2}$

In children and adolescents, prehypertension is defined by a systolic and/or diastolic BP at the 90th percentile but less than the 95th percentile for age, gender, and height according to normative tables published in the Working Group report. Multiple longitudinal studies have established that BP levels track with age such that childhood BP levels are associated with BP levels in later life. ${ }^{3}$ Divergent from adult treatment 
strategies, monitoring of adolescent prehypertension requires 6-monthly evaluations and recommendation of lifestyle changes. ${ }^{4,5}$

More than $95 \%$ of human hypertension cannot be explained, is due to unknown causes, and is termed "essential" or "primary" hypertension. This paper reviews both internal (ie, gender, age, and race) and external (ie, modifiable risk factors and medication) factors determining development of prehypertension and the strategies used at present to combat prehypertension (lifestyle changes and medication) for individuals of all ages.

\section{Internal factors}

Women, unlike men, show an abrupt increase in BP around the fifth decade of life, and by the sixth decade surpass men in the incidence of primary hypertension. ${ }^{6}$ Recently, Sandberg et al have shown several gender differences related to sex chromosomes and the role that hormones play in the development of primary hypertension. ${ }^{7}$ Studies using a four-core genotype mouse model that isolates specific sex chromosome effects from gonadal sex effects show greater elevations in BP in gonadectomized XX mice than gonadectomized XY mice. ${ }^{7,8}$ The authors suggest that the XX sex chromosomes may have an adverse effect in the absence of sex hormones, leading to the higher prevalence of elevated BP in this population. ${ }^{8}$ Researchers have not been able to separate the effects of sex hormones from the effects of aging on arterial pressure, mainly because sex steroid concentrations decrease in humans as they age. The search for aging mechanisms highlights the need for research within the adolescent population, especially in view of the fact that prehypertension rates are increasing in children and adolescents, with a current prevalence ranging from $3 \%$ to $5 \% .{ }^{4} \mathrm{McNiece}$ et $\mathrm{al}^{9}$ reported a higher prevalence of prehypertension among both Afro-American and Hispanic adolescents when compared with their white non-Hispanic counterparts, but this association has not been confirmed in other studies. ${ }^{10}$ Although estimates of progression from prehypertension to hypertension do exist, they vary considerably ( $1 \%-7 \%$ increase per year), but it is important to note that even the low end of such estimates would yield annual increases of 119,000 adolescents (http:// www.census.gov) being counted as hypertensive. This figure is startling because it has been shown that being classified as prehypertensive does not just act as a forerunner to a person becoming hypertensive, it is also associated with the presence of active disease. Some adolescents with prehypertension already demonstrate evidence of target organ damage.
Left ventricular hypertrophy is the most widely recognized abnormality attributed to high BP in children. ${ }^{4}$ Earlier supervised, play-based exercise interventions seem necessary to prevent prehypertension and start more children on a healthy active lifestyle, in the hope that they will maintain this into adulthood. Increased participation in physical education at school is normally considered to be the start of this, but a recent study has found that supervised play-based physical activity during the summer break has a beneficial effect on the metabolic profile and cardiovascular end points. ${ }^{11,12}$

In terms of ethnic variables, the NHANES (National Health and Nutrition Examination Survey) III found no difference in the prevalence of prehypertension between nonHispanic whites, non-Hispanic blacks, Mexican Americans, and others, ${ }^{13}$ whereas the more recent REGARDS (REasons for Geographic And Racial Differences in Stroke) study in 2011 found that the prevalence of prehypertension was higher in Afro-Americans than in whites (62.9\% versus 54.1, respectively). ${ }^{14,15}$ Further, the NHANES III report stated that men were more likely to have prehypertension than women (40\% versus $2 \%$ ) and prehypertension was higher in individuals with overweight/obesity. The REGARDS study also reported a higher prevalence of prehypertension in obese individuals and those with heavy alcohol consumption. ${ }^{15}$ However, these results are misleading in view of the gender differences that exist, ie, women demonstrate the greatest prevalence of prehypertension and increased rates of cardiovascular disease with advancing age. Gender differences may be related to higher heart rates and earlier reflected pulse waves leading to higher BP and pulse pressures in women, and these changes may be linked to gender differences in the extent of perturbation of the renin-angiotensin-aldosterone system (RAAS). ${ }^{7}$

\section{Medication}

A seminal study reported in 2006 examined the effectiveness of prescribing an angiotensin II blocker in patients with prehypertension. ${ }^{16}$ The results of this study support the idea that essential hypertension can be prevented or delayed, showing a $26 \%$ reduction in the number of subjects prescribed this treatment presenting with hypertension compared with those given placebo. ${ }^{16}$ In 2008 , the authors resubmitted their findings to conform to contemporary BP measurement protocols (two consecutive elevated measurements instead of three) and found outcomes similar to those in the previous study. Regardless of the algorithm used to determine hypertension, both methods agree that treatment of prehypertensive BP can markedly reduce or completely avoid the 
development of essential hypertension. ${ }^{17}$ It should be noted that more than two thirds of individuals with hypertension cannot adequately control their BP with one medication and require two or more antihypertensive agents from different drug classes for effective control. ${ }^{1}$

Physicians are generally in agreement that antihypertensive treatment begins with lifestyle modification, but if the BP goal is not achieved, thiazide-type diuretics should be used as initial therapy for most patients, either alone or in combination with one of the other classes, ie, angiotensinconverting enzyme inhibitors, angiotensin receptor blockers, beta-blockers, or calcium channel blockers. Several randomized, controlled trials have shown that this treatment regimen will reduce one or more hypertensive complications.

The RAAS have been implicated in the development of hypertension. Activation of the RAAS system leads to endothelial dysfunction and inflammation by promoting release of angiotensin I, which induces vascular injury via several mechanisms, including vasoconstriction, cell growth, oxidative stress, and inflammation (inducing release of cytokines and proinflammatory transcription factors).${ }^{18}$ These mechanisms contribute to a prothrombotic state, plaque buildup, and instability, ultimately leading to plaque rupture. Currently, widespread use of angiotensin-converting enzyme inhibitors are administered to millions of patients, to great effect. In addition to this, it is now thought that these agents promote upstream blockade of overformation of renin and/or its precursors, preprorenin and prorenin. This change in thinking has come from the discovery of the renin receptor, that stimulates the formation of angiotensin II, which is able to bind prorenin equally as well. Angiotensin II inhibitors have been shown to be as effective as diuretics. ${ }^{19}$ It is well known that the sympathetic nervous system strongly influences the RAAS, which is activated by many common comorbidities, including type 2 diabetes, hyperinsulinemia, excess weight, and a diet rich in carbohydrates and fats. Interestingly, two large clinical trials ${ }^{20,21}$ have shown that angiotensinconverting enzyme inhibitors decrease the risk of developing type 2 diabetes in patients with hypertension and/or vascular disease. Drug type and time of dosage determines the time course of BP suppression. ${ }^{22}$ Overall, pharmacological intervention in prehypertensives has yielded mixed results, with some researchers showing benefits ${ }^{23}$ while others have not. ${ }^{24}$ It seems that the existence of comorbidities determines whether a prehypertensive patient is likely to respond to pharmacological intervention. ${ }^{25}$ However, it has been shown that both young ( $<65$ years) and older ( $>65$ years) patients may achieve some benefit from a course of antihypertensive pharmacologic intervention, although the absolute change and cost-effectiveness may be greater in older patients, who often present with more pronounced risk factors. ${ }^{23}$

\section{Intermediate factors Obesity}

Many causal factors for elevated BP have been identified, including excess body weight, excess sodium intake, reduced physical activity, inadequate intake of fruit, vegetables, and potassium, and excess alcohol intake. JNC-7 reports that the prevalence of these factors is high. At least 122 million Americans are overweight or obese. Being classified as either overweight or obese is a major worldwide risk factor for prehypertension and hypertension (Guo et al, 2011). ${ }^{26}$ Average sodium intake is nearly twice what is recommended for men and elevated for women, and much of this comes from processed foods. Females consume an amount of sodium which is elevated beyond the daily recommendation, while males consume over twice that amount. Less than $20 \%$ of Americans engage in regular physical activity and less than $25 \%$ consume the recommended amount of fruit and vegetables.

\section{Leptin}

Plasma leptin concentration correlates positively with adiposity, ${ }^{27}$ and hyperleptinemia is an independent risk factor for coronary artery disease ${ }^{28}$ and a strong predictor of myocardial infarction. ${ }^{29}$ Additionally, leptin has been implicated in the formation of inflammatory cytokines and calcification of vascular smooth muscle cells. ${ }^{30}$ Leptin receptors are known to be expressed in coronary arteries, and hyperleptinemia causes significant endothelial dysfunction. ${ }^{31}$ One study reported marked increases in body weight $(66.2 \mathrm{~kg} \pm 12.6$ to $69.4 \mathrm{~kg} \pm 13.5$ ) over the course of 4 weeks, noting a concomitant increase in leptin release during the night. ${ }^{32}$

\section{External factors}

The increasing incidence of hypertension and cardiovascular disease has been related to changes in lifestyle and dietary patterns ${ }^{33}$ which could be sodium-related, given that communities that do not consume large amounts of sodium do not see the same age-associated rise in BP. Under an unnatural overload of dietary sodium, the kidneys switched their handling from retention to excretion. This increase in sodium results in extracellular volume expansion, increased cardiac output, and subsequently increased peripheral resistance. Chronic BP elevation may result in end organ damage. In the kidneys, the loss of glomeruli and renal arterioles may exacerbate natriuresis and further elevate BP due to dysregulation of 
the RAAS. However, several factors play a role in sodium sensitivity, including race and ethnicity, making BP control difficult to achieve with pharmacological intervention. Further, with approximately $17 \%$ (or 12.5 million) of children and adolescents aged 2-19 years now being obese, it is well recognized that earlier onset of drug therapy will not attenuate the increasing incidence of hypertension if obesity and inactive lifestyles continue to increase. ${ }^{34}$ Also, as our population ages, vascular hypertrophy resulting from advancing atherosclerosis may diminish responsiveness to antihypertensive medications. ${ }^{35}$

At the forefront of BP research is the need to develop studies aimed at elucidating the time point at which human arterial health is compromised, and to develop meaningful studies that lead to prevention of prehypertension and avoidance of progression to the need for pharmacological intervention. Also, the development of studies to replace pharmacological therapy in those on current treatment given that lifestyle modification can be used as a prevention/treatment for several other factors contributing to prehypertension. Daily living can impact on BP to a great extent, so there is a need for reliable and repeatable measurements. ${ }^{36}$ Compounding this issue is the fact that many physicians fail to follow best testing measures when taking BP, resulting in variable and often high estimates. This may lead to the start of patienthood if pharmacologic action is prescribed which has shown to increase job absenteeism, leading to economic impact in insurance costs for the company and increased healthcare costs. ${ }^{37}$

\section{Lifestyle habits}

Most individuals with prehypertension have one or more concomitant conditions associated with increased cardiovascular risk. The NHANES II and the NHANES II Mortality Study showed that $90 \%$ of individuals with prehypertension have at least one other cardiovascular risk factor. ${ }^{38}$ These risk factors include the dyslipidemias, an early family history of cardiovascular disease, cigarette smoking, abdominal obesity, hyperinsulinemia and insulin resistance, impaired fasting glucose, a prothrombic state, endothelial dysfunction, and impaired vascular distensibility.

As previously stated, modest consumption of alcohol, ie, $<30$ g of ethanol a day or approximately two "drinks" daily for men and one containing $<15 \mathrm{~g}$ of ethanol for women, is not generally associated with increases in BP. Ingestion of larger quantities of alcohol has a dose-related effect on BP, both in hypertensive and normotensive subjects. ${ }^{39}$ Tobacco use, specifically cigarette smoking, increases BP and is an independent risk factor for cardiovascular disease.
Although conflicting data have been reported, a 2011 meta-analysis indicated that alcohol and tobacco intake were related to development of hypertension (Gao et al, 2011). In addition to BP changes, cigarette smoking and second-hand exposure to cigarette smoke increase all-cause mortality in both males and females by about $1 \%{ }^{40}$

It is well known that poor cardiorespiratory fitness is a strong and independent predictor of cardiovascular disease and all-cause mortality, and higher activity levels equate to higher cardiorespiratory fitness, which is also correlated with lower resting BP, making exercise an antihypertensive lifestyle modification. In fact, meta-analyses of exercisebased cardiac rehabilitation studies have shown reductions in mortality of up to $32 \%$, and exercise alone has been associated with a $30 \%$ reduction in cardiac risk, making it similar to statin and antihypertensive interventions. ${ }^{41-44}$

It was proposed by Green that exercise provides cardioprotection by protecting the vascular wall and that increased transient bouts of sheer stress confer a "vascular conditioning" effect. ${ }^{45}$ Increases in endothelial nitric oxide synthase levels lead to increased bioavailability of nitric oxide, a powerful vasodilator that reduces BP by decreasing vessel resistance. Repeated bouts of exercise lead to a resetting of the baroreflex to lower operating pressures which, in turn, lowers resting BP. With its ability to achieve a mean reduction of $3 \mathrm{mmHg}$ in both systolic and diastolic BP, either mode of exercise serves a form of treatment for the prehypertensive subject, and also improves the autonomic, renin-angiotensin-aldosterone, and skeletal muscle systems, without any side effects.

A large number of studies have been performed to examine the effects of aerobic and/or resistance exercise on BP in hypertensive, prehypertensive, and normotensive groups, and a recent review has examined the relevant findings. ${ }^{46}$ Independent of weight loss, exercise has been shown to decrease BP. ${ }^{47,48}$ However, studies using conventional measurements show more agreement, whereas those utilizing ambulatory BP monitoring have yielded more conflicting results. In a meta-analysis of 54 randomized controlled studies including intervention and control groups which differed only in aerobic exercise, aerobic exercise was associated with a statistically significant reduction in BP of 3.8/2.6 mmHg. This change was seen in both normotensive and hypertensive patients. ${ }^{49}$

Another meta-analysis examining resistance exercise showed a $3 \pm 3 / 3 \pm 2 \mathrm{mmHg}$ decrease in BP in studies lasting at least 4 weeks. ${ }^{50}$ However, resistance exercise has been shown to increase arterial stiffness, which discredits its use as an antihypertensive exercise, and the American 
Heart Association states that resistance exercise should only be undertaken if complementing a good aerobic-based exercise program. In direct comparison with aerobic exercise programs, recent studies have shown that resistance exercise yields comparable hemodynamic results with slight increases in resting heart rates. ${ }^{51}$ Also, gender differences exist, such that only men have been shown to develop increased arterial stiffness, ${ }^{47}$ leaving resistance exercise an excellent choice for prehypertensive women, with the additional benefits of prevention or amelioration of osteoporosis as a result of weight-bearing exercise.

Weight loss has been shown to be the most effective lifestyle strategy for prevention of hypertension, ${ }^{52}$ and addition of antihypertensive medication has been shown to have an effect on $\mathrm{BP}$ reduction that is additive to that achieved by weight loss alone. ${ }^{53}$ However, it has been shown that the type of medication prescribed may decrease the ability of the patient to lose weight. ${ }^{52}$ A substudy of the DASH (Dietary Approaches to Stop Hypertension) trial also showed that by reducing sodium intake to less than $100 \mathrm{mmol}$ in your daily diet, in addition to dietary changes provided greater benefit than either approach alone. ${ }^{54}$ The JNC-7 also found that two or more intervention treatments worked better than any individual strategy used alone to reduce BP.

For overall risk reduction it is advised that a patient stop smoking, and a myriad of other methods are also available to reduce BP. Dietary intervention is the most effective of the lifestyle measures for reducing high BP. Adhering to the DASH diet, which is high in fruit, vegetables, and low-fat dairy products, can reduce BP by $8-14 \mathrm{mmHg}$. Further, reduction in sodium intake and body weight can reduce BP by $2-8 \mathrm{mmHg}$ and $5-20 \mathrm{mmHg}$, respectively. Moderating alcohol intake to the recommended levels of no more than one or two drinks per day for women and men, respectively, can lower BP by 2-4 mmHg. Additional lifestyle factors, such as physical activity, have a large impact on BP, being able to reduce systolic BP by 4-9 $\mathrm{mmHg}$. However, outside of controlled clinical trials, the efficacy of dietary adherence becomes marginal, with much of the improvement in body weight, sodium intake, and BP lost within 36 months. ${ }^{55}$ The PREMIER study mirrored these results, with the DASH diet being only moderately effective compared with clinical trials. ${ }^{56}$ A meta-analysis was performed, reporting that the efficacy of simply giving instructions and guidance on diet became negligible in clinical trials lasting over 6 months. ${ }^{57}$

\section{Clinical procedures}

Logistic problems exist when measuring the physiological parameter of BP. Proper sizing of the arm cuff during manual measurement using a stethoscope and sphygmomanometer is crucial, because an undersized cuff results in consistent overestimation of diastolic BP by approximately $6 \mathrm{mmHg}$. Inaccurate sphygmomanometers are also common, with $30 \%-40 \%$ of aneroid sphygmomanometers used by physicians being out of calibration by $4 \mathrm{mmHg}$ or more, and about $10 \%$ being out of calibration by $10 \mathrm{mmHg}$ or more. ${ }^{36}$ Also, gender differences exist with regard to the emotional phenomenon known as "white coat" hypertension, which is characterized by increased sympathetic stimulation and RAAS activity resulting in systolic and diastolic BP elevations of at least $20 / 10 \mathrm{mmHg}$, respectively, when a clinician is present. Therefore, there may be an additional need for ambulatory monitoring in women or more care during the clinical assessment of resting BP for more accurate prescriptions.

\section{Conclusion}

Antihypertensive medications can reduce BP immediately, yet their prescription would enroll more than 25 million Americans into patienthood and also place a great burden on the health insurance system. Given that exercise has been found to be as effective as medication with little or no side effects and that exercise works on multiple physiological systems, the most effective strategy may be to enroll children into sports to develop exercise habits that will last lifelong as a means to prevent prehypertension. Our goal is to use exercise as a daily medication that fits every individual worldwide. The challenge is to change the current school of thought that exercise, as a therapy, is only used for a short while until symptoms disappear.

\section{Disclosure}

The authors report no conflicts of interest in this work.

\section{References}

1. Chobanian AV, Bakris GL, Black HR, et al. The Seventh Report of the Joint National Committee on Prevention, Detection, Evaluation, and Treatment of High Blood Pressure: the JNC 7 report. JAMA. 2003;289(19):2560-2572.

2. Fuchs FD. Prehypertension: the rationale for early drug therapy. Cardiovasc Ther. 2010;28(6):339-343.

3. Chen X, Wang Y. Tracking of blood pressure from childhood to adulthood: a systematic review and meta-regression analysis. Circulation. 2008;117(25):3171-3180.

4. Redwine KM, Daniels SR. Prehypertension in adolescents: risk and progression. J Clin Hypertens (Greenwich). 2012;14(6):360-364.

5. Redwine KM, Acosta AA, Poffenbarger T, Portman RJ, Samuels J. Development of hypertension in adolescents with pre-hypertension. J Pediatr. 2012;160(1):98-103.

6. Burt VL, Whelton P, Roccella EJ, et al. Prevalence of hypertension in the US adult population. Results from the Third National Health and Nutrition Examination Survey, 1988-1991. Hypertension. 1995;25(3):305-313. 
7. Sandberg K, Ji H. Sex differences in primary hypertension. Biol Sex Differ. 2012;3(1):7.

8. Ji H, Zheng W, Wu X, et al. Sex chromosome effects unmasked in angiotensin II-induced hypertension. Hypertension. 2010;55(5): $1275-1282$.

9. McNiece KL, Poffenbarger TS, Turner JL, Franco KD, Sorof JM, Portman RJ. Prevalence of hypertension and pre-hypertension among adolescents. J Pediatr. 2007;150(6):640-644.

10. Jago R, Harrell JS, McMurray RG, Edelstein S, El Ghormli L, Bassin S. Prevalence of abnormal lipid and blood pressure values among an ethnically diverse population of eighth-grade adolescents and screening implications. Pediatrics. 2006;117(6):2065-2073.

11. Collier SR, Curry CD, Meucci M, Welsh J, Cook CB. Metabolomic signatures of 8 weeks of play-based exercise vs. controls in overweight adolescent children. Med Sci Sports Exerc. 2012;44(5):1977.

12. Meucci M, Curry CD, Baldari C, Guidetti L, Cook C, Collier SR. Effect of Play-based Summer Break Exercise on Cardiovascular Function in Adolescents. Acta Paediatr. 2012; In Press.

13. Wang Y, Wang QJ. The prevalence of prehypertension and hypertension among US adults according to the new joint national committee guidelines: new challenges of the old problem. Arch Intern Med. 2004;164(19):2126-2134.

14. Pavlik VN, Hyman DJ, Doody R. Cardiovascular risk factors and cognitive function in adults 30-59 years of age (NHANES III). Neuroepidemiology. 2005;24(1-2):42-50.

15. Glasser SP, Judd S, Basile J, et al. Prehypertension, racial prevalence and its association with risk factors: Analysis of the REasons for Geographic And Racial Differences in Stroke (REGARDS) study. Am J Hypertens. 2011;24(2):194-199.

16. Julius S, Nesbitt SD, Egan BM, et al. Feasibility of treating prehypertension with an angiotensin-receptor blocker. $N$ Engl J Med. 2006;354(16): 1685-1697.

17. Julius S, Kaciroti N, Egan BM, Nesbitt S, Michelson EL. TROPHY study: Outcomes based on the Seventh Report of the Joint National Committee on Hypertension definition of hypertension. J Am Soc Hypertens. 2008;2(1):39-43.

18. Ji H, Menini S, Zheng W, Pesce C, Wu X, Sandberg K. Role of angiotensin-converting enzyme 2 and angiotensin(1-7) in 17betaoestradiol regulation of renal pathology in renal wrap hypertension in rats. Exp Physiol. 2008;93(5):648-657.

19. [No authors listed]. Major outcomes in high-risk hypertensive patients randomized to angiotensin-converting enzyme inhibitor or calcium channel blocker vs diuretic: the Antihypertensive and LipidLowering Treatment to Prevent Heart Attack Trial (ALLHAT). JAMA. 2002;288(23):2981-2997.

20. [No authors listed. ACE inhibitor even prevents diabetes. Sensational HOPE study]. MMW Fortschr Med. 1999;141(39):6. German.

21. Scheen AJ. Clinical study of the month. The CAPPP study: "The Captopril Prevention Project”. Rev Med Liege. 1999;54(3):197-199. French.

22. White WB. Clinical assessment of early morning blood pressure in patients with hypertension. Prev Cardiol. 2007;10(4):210-214.

23. Pimenta E, Oparil S. Prehypertension: epidemiology, consequences and treatment. Nat Rev Nephrol. 2010;6(1):21-30.

24. Staessen JA, Richart T, Wang Z, Thijs L. Implications of recently published trials of blood pressure-lowering drugs in hypertensive or high-risk patients. Hypertension. 2010;55(4):819-831.

25. Ventura HO, Lavie CJ. Antihypertensive therapy for prehypertension: relationship with cardiovascular outcomes. JAMA. 2011;305(9): 940-941.

26. Guo X, Zou L, Zhang X, et al. Prehypertension: a meta-analysis of the epidemiology, risk factors, and predictors of progression. Tex Heart Inst J. 2011;38(6):643-652

27. Friedman JM. Leptin, leptin receptors, and the control of body weight. Nutr Rev. 1998;56(2 Pt 2):s38-s46.

28. Ren J. Leptin and hyperleptinemia - from friend to foe for cardiovascular function. J Endocrinol. 2004;181(1):1-10.
29. Soderberg S, Ahren B, Jansson JH, et al. Leptin is associated with increased risk of myocardial infarction. J Intern Med. 1999;246(4): 409-418.

30. Parhami F, Tintut Y, Ballard A, Fogelman AM, Demer LL. Leptin enhances the calcification of vascular cells: artery wall as a target of leptin. Circ Res. 2001;88(9):954-960.

31. Knudson JD, Dincer UD, Zhang C, et al. Leptin receptors are expressed in coronary arteries, and hyperleptinemia causes significant coronary endothelial dysfunction. Am J Physiol Heart Circ Physiol. 2005;289(1): H48-H56.

32. Schmid DA, Wichniak A, Uhr M, et al. Changes of sleep architecture, spectral composition of sleep EEG, the nocturnal secretion of cortisol, $\mathrm{ACTH}, \mathrm{GH}$, prolactin, melatonin, ghrelin, and leptin, and the DEX$\mathrm{CRH}$ test in depressed patients during treatment with mirtazapine. Neuropsychopharmacology. 2006;31(4):832-844.

33. Grassi DG. Treating prehypertension. $N$ Engl J Med. 2006;355(4):416.

34. Ogden CL, Carroll MD, Curtin LR, Lamb MM, Flegal KM. Prevalence of high body mass index in US children and adolescents, 2007-2008. JAMA. 2010;303(3):242-249.

35. Levy D, Larson MG, Vasan RS, Kannel WB, Ho KK. The progression from hypertension to congestive heart failure. JAMA. 1996;275(20): $1557-1562$

36. Campbell NR, McKay DW. Accurate blood pressure measurement: why does it matter? CMAJ. 1999;161(3):277-278.

37. Haynes RB, Sackett DL, Taylor DW, Gibson ES, Johnson AL. Increased absenteeism from work after detection and labeling of hypertensive patients. N Engl J Med. 1978;299(14):741-744.

38. Mainous AG 3rd, Everett CJ, Liszka H, King DE, Egan BM. Prehypertension and mortality in a nationally representative cohort. Am J Cardiol. 2004;94(12):1496-1500.

39. Whelton PK, He J, Appel LJ, et al. Primary prevention of hypertension: clinical and public health advisory from The National High Blood Pressure Education Program. JAMA. 2002;288(15):1882-1888.

40. White WB. Smoking-related morbidity and mortality in the cardiovascular setting. Prev Cardiol. 2007;10(2 Suppl 1):1-4.

41. Taylor RS, Brown A, Ebrahim S, et al. Exercise-based rehabilitation for patients with coronary heart disease: systematic review and meta-analysis of randomized controlled trials. Am J Med. 2004;116(10): 682-692.

42. Thompson PD, Buchner D, Pina IL, et al. Exercise and physical activity in the prevention and treatment of atherosclerotic cardiovascular disease: a statement from the Council on Clinical Cardiology. Circulation. 2003;107(24):3109-3116

43. Turnbull F. Effects of different blood-pressure-lowering regimens on major cardiovascular events: results of prospectively-designed overviews of randomised trials. Lancet. 2003;362(9395): 1527-1535.

44. Wilt TJ, Bloomfield HE, MacDonald R, et al. Effectiveness of statin therapy in adults with coronary heart disease. Arch Intern Med. 2004;164(13):1427-1436.

45. Green DJ. Exercise training as vascular medicine: direct impacts on the vasculature in humans. Exerc Sport Sci Rev. 2009;37(4):196-202.

46. Hedayati SS, Elsayed EF, Reilly RF. Non-pharmacological aspects of blood pressure management: what are the data? Kidney Int. 2011;79(10): 1061-1070

47. Collier SR, Frechette V, Sandberg K, et al. Sex differences in resting hemodynamics and arterial stiffness following 4 weeks of resistance versus aerobic exercise training in individuals with pre-hypertension to stage 1 hypertension. Biol Sex Differ. 2011;2(1):9.

48. Collier SR, Kanaley JA, Carhart R Jr, et al. Effect of 4 weeks of aerobic or resistance exercise training on arterial stiffness, blood flow and blood pressure in pre- and stage-1 hypertensives. $J$ Hum Hypertens. 2008;22(10):678-686.

49. Whelton SP, Chin A, Xin X, He J. Effect of aerobic exercise on blood pressure: a meta-analysis of randomized, controlled trials. Ann Intern Med. 2002;136(7):493-503.

50. Kelley GA, Kelley KS. Progressive resistance exercise and resting blood pressure: a meta-analysis of randomized controlled trials. Hypertension. 2000;35(3):838-843. 
51. Collier SR, Diggle MD, Heffernan KS, Kelly EE, Tobin MM, Fernhall B. Changes in arterial distensibility and flow-mediated dilation after acute resistance vs aerobic exercise. $J$ Strength Cond Res. 2010;24(10):2846-2852.

52. Stevens VJ, Corrigan SA, Obarzanek E, et al. Weight loss intervention in phase 1 of the Trials of Hypertension Prevention. The TOHP Collaborative Research Group. Arch Intern Med. 1993;153(7):849-858.

53. Elmer PJ, Grimm R Jr, Laing B, et al. Lifestyle intervention: results of the Treatment of Mild Hypertension Study (TOMHS). Prev Med. 1995;24(4):378-388.

54. Sacks FM, Svetkey LP, Vollmer WM, et al. Effects on blood pressure of reduced dietary sodium and the Dietary Approaches to Stop Hypertension (DASH) diet. DASH-Sodium Collaborative Research Group. N Engl J Med. 2001;344(1):3-10.
55. [No authors listed]. Effects of weight loss and sodium reduction intervention on blood pressure and hypertension incidence in overweight people with high-normal blood pressure. The Trials of Hypertension Prevention, phase II. The Trials of Hypertension Prevention Collaborative Research Group. Arch Intern Med. 1997;157(6):657-667.

56. Appel LJ, Moore TJ, Obarzanek E, et al. A clinical trial of the effects of dietary patterns on blood pressure. DASH Collaborative Research Group. N Engl J Med. 1997;336(16):1117-1124.

57. Hooper M. What do you think is a non-disease? Diet, lifestyle, exercise, spirituality, and the search for meaning are ignored at our peril. $B M J$ 2002;324(7342):912.

\section{Publish your work in this journal}

Vascular Health and Risk Management is an international, peerreviewed journal of therapeutics and risk management, focusing on concise rapid reporting of clinical studies on the processes involved in the maintenance of vascular health; the monitoring, prevention and treatment of vascular disease and its sequelae; and the involvement of metabolic disorders, particularly diabetes. This journal is indexed on PubMed Central and MedLine. The manuscript management system is completely online and includes a very quick and fair peer-review system, which is all easy to use. Visit http://www.dovepress.com/ testimonials.php to read real quotes from published authors.

Submit your manuscript here: http://www.dovepress.com/vascular-health-and-risk-management-journal 